\title{
RECENT CRUSTAL RUPTURE FIELD IN CHINA AND THE PROBLEM OF STRONG- EARTHQUAKE PREDICTION
}

\author{
Guoyu Ding \\ State Seismological Bureau, Beijing, China \\ (Received June 22, 1985; Revised May 7, 1986)
}

\begin{abstract}
A fundamental problem of carrying out earthquake prediction lies in the correct identification of a potential active area of strong earthquake activity. To attain this goal, it is necessary to study the state of a recent crustal rupture field related to strong earthquake activity. Large amounts of data have been acquired on historical earthquakes, active faults, surface faults associated with earthquakes, isoseismal lines, and source mechanisms in China. All these data outline objectively the principal pattern of recent crustal ruptures related to strong earthquake activity in China. It shows that this kind of crustal rupturing is characterized by rupturing in zones and regions. Four such major zones could be outlined. They are the Central Asian zone, the North-South zone, the North China zone, and the Southeastern Coast zone. Studies on the distribution, characteristics of activity, and mechanisms of the rupture zones, and recurrence interval of strong earthquakes in these zones have become of considerable significance for strong earthquake prediction.
\end{abstract}

\section{Introduction}

Since the large-scale earthquake prediction study started in China in 1966, identification of areas of potential strong earthquakes $(M \geqslant 7)$ has occupied an important place in the studies, because earthquakes are distributed extensively in this vast country. Without solving this problem, observation of various precursors could never be effected. It is especially true for seismic hazard assessments. Therefore, correct determination of such areas becomes essential in earthquake prediction. In solving this problem, the study of active faults (or late Quaternary faults) plays an obvious part. It provides an important criterion for the identification of strong earthquake areas. Based on the distribution and length of active faults, their slip rate, and the recurrence intervals of strong earthquakes, the assessment of the hazard of future strong earthquakes could not only reduce the area for detecting earthquake precursors, but also help to make arrangements of research work more effective (MATSUDA, 1977). As there are two modes of movement of active faults, namely stick-slip and creep, seismicity along an active fault varies considerably. Moreover, there is no strong earthquake activity at all along many active faults. So to find out the segments with potential hazard in the near future from many extensively distributed active faults, emphasis should be laid on the studies of the state and regularity of the recent crustal rupturing, and on the discrimination of stick-slip segments from creeping segments. It will improve our understanding of the laws governing strong earthquakes on these active faults and the intervals of their recurrence. Based on data of active faults, surface 
faults, associated with an earthquake, isoseismal lines and source mechanisms, this paper delineates the distribution of recent crustal rupture zones and rupture areas related to strong earthquakes within the continent of China, and the characteristics of rupturing. The recurrence interval of strong earthquakes is also discussed in the paper.

\section{Data}

Active faults in China are distributed very widely. At present, a series of regional maps of active faults has been compiled, and a new map covering the whole country is in progress. Taking 105 degrees east longitude as the border line, the whole country may be divided into two parts, the eastern and the western parts. In the eastern part, normal faults and normal strike-slip faults striking NE to NNE are dominant. Whereas in the west, there are mainly NW- and NNW-striking faults of strike-slip and thrust types. Seismicity in Middle China and South China is comparably low, and the size of largest earthquake is smaller. But there are still some active faults along the southeast coast (Fig. 1).

A somewhat quantitative understanding of displacement and slip rates of active faults has been acquired based on the data obtained up to the present. In general, it seems that since late-Pliocene or early Pleistocene, the total horizontal displacement is larger in the west, from several kilometers to ten or twenty kilometers or even greater, whereas the displacement in the east is much smaller, from several meters to several kilometers (DING, 1984). The average slip rate in North China is less than $1 \mathrm{~mm}$ to several millimeters per year (Fig. 1). In the west, the slip rate is much greater, reaching from several to over ten millimeters per year. The vertical displacement during the same time interval is much

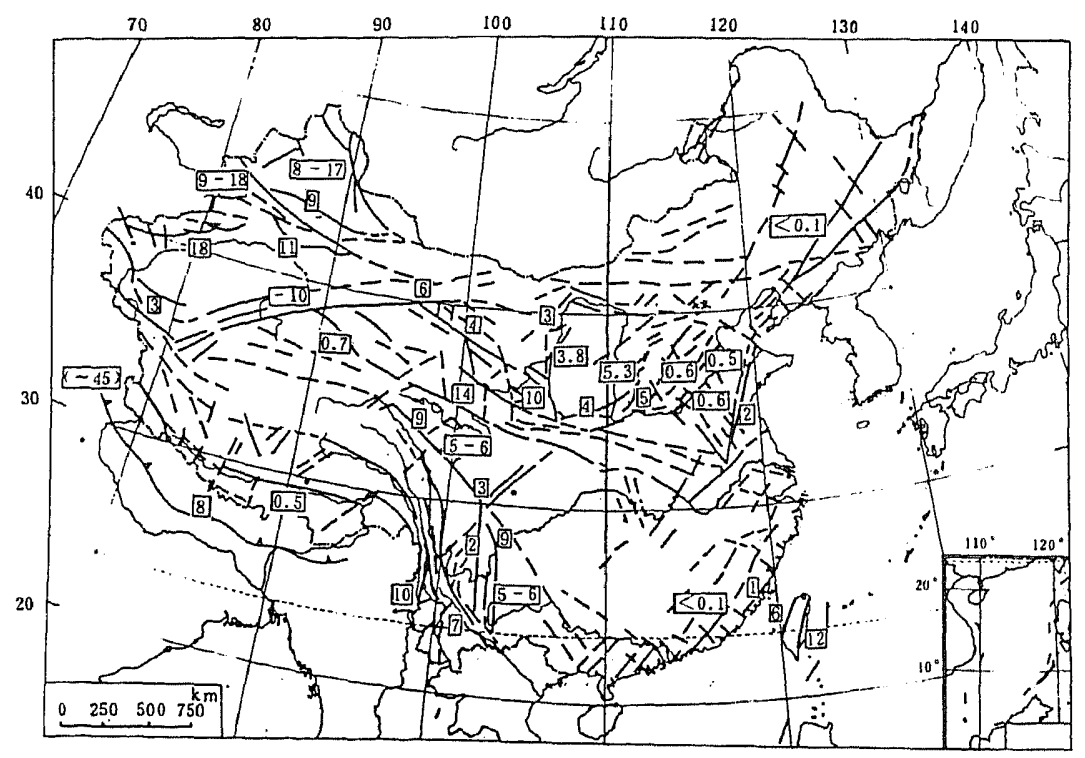

Fig. 1. Active fault distribution in China and its horizontal slip-rates ( $\mathrm{mm} / \mathrm{yr})$. 


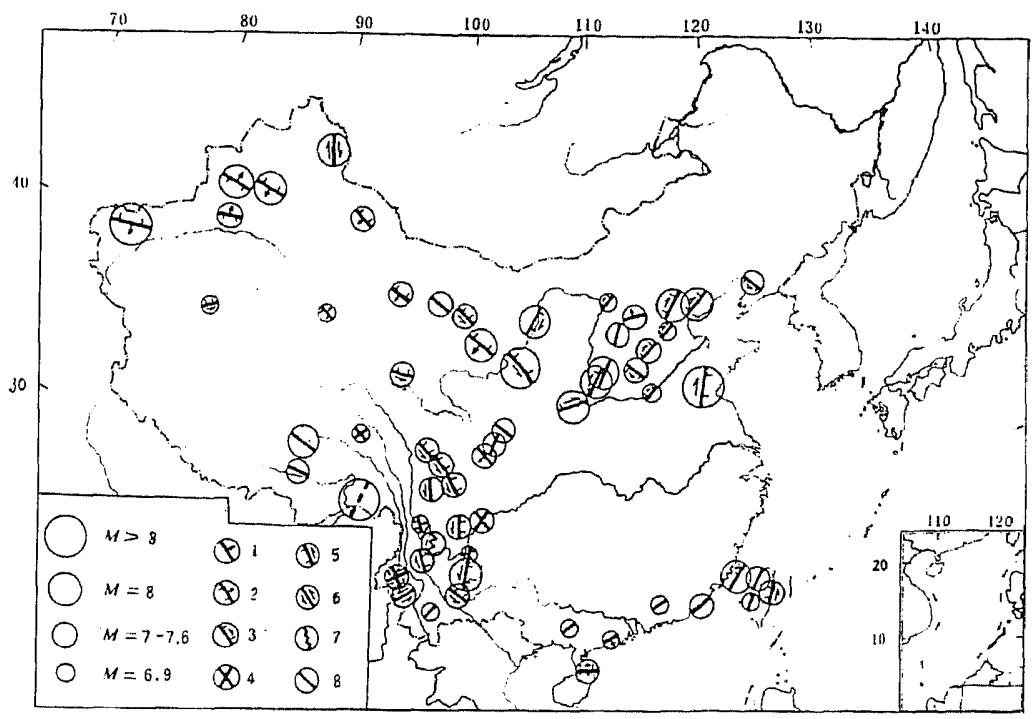

Fig. 2. Surface faults associated with earthquakes in China and their rupture characteristics. 1, Normal fault; 2 , thrust fault; 3 , normal strike-slip fault; 4, a set of conjugate faults; 5 , reverse strike-slip fault; 6 , strike-slip fault; 7 , surface cracking; 8 , characteristics unknown.

smaller than the horizontal displacement. It is about several hundreds to $1,000 \mathrm{~m}$ in East China, several tens to several hundreds of meters in South China, and 3,000 to $4,000 \mathrm{~m}$ in West China. The ratio of vertical displacement to horizontal displacement is about $1: 2$ in North China, and 1:6 or even 1:10 in West China. The distribution of active faults in the whole country constitutes the fundamental frame of the recent rupturing field. A comparison of the map of strong earthquake distribution (Fig. 4) with that of the active faults distribution (Fig. 1) clearly shows that strong earthquake activity is related to active faults. But there are other active faults without any records of strong earthquakes.

The surface faults associated with strong earthquakes (or earthquake faults) reflect more visually the concrete conditions of the recent crustal rupturing. In the innerland of China, most earthquakes of $M=6.5$ produced obvious surface faults. Analyses of these faults provide the most immediate bases for understanding the recent crustal rupturing field in the innerland of China and the laws governing strong earthquake activity.

Large amounts of data on earthquake surface faults have been accumulated (Fig. 2). From about 60 known earthquake faults, one can see that most of them are strike-slip faults, including types of pure strike-slip, normal strike-slip, and reverse strike-slip. They are distributed widely in various places. And the normal earthquake faults are mainly distributed in North China and Tibet. Thrust faults are mainly in the western part of China. The strikes of most earthquake faults are coincident with those of main tectonics of a region. Some conjugate sets of earthquake ruptures, however, are related to the secondary structures of a region.

A great deal of information on isoseismal lines and focal mechanisms also provided 


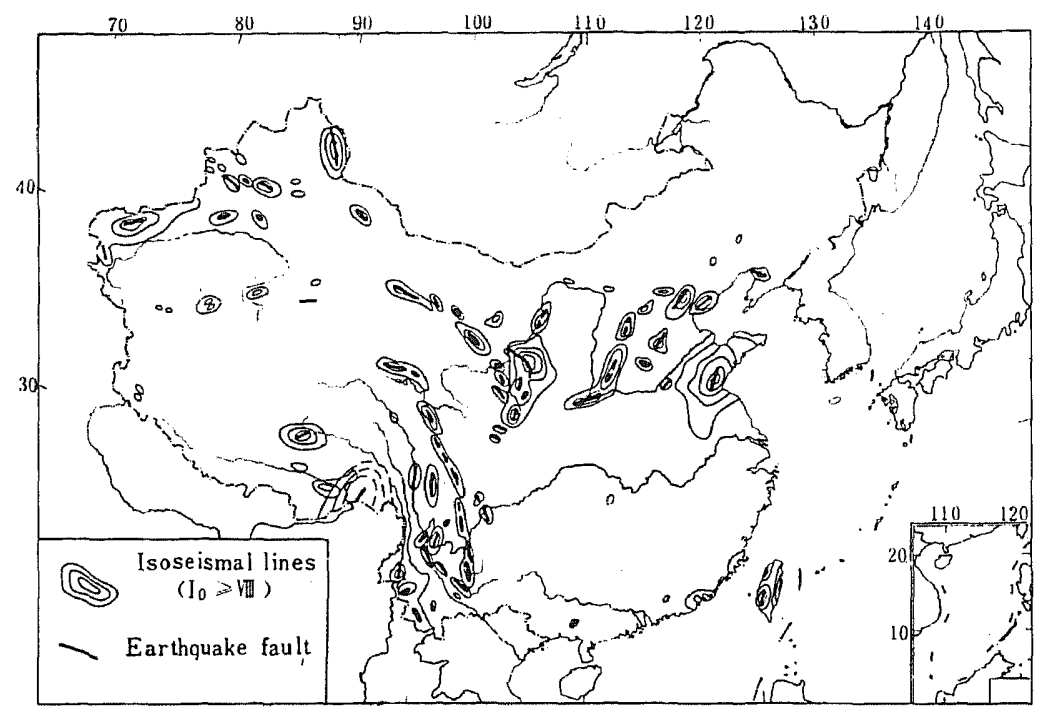

Fig. 3. Simplified map of isoseismal lines $\left(I_{0}=\right.$ VIII) of strong earthquakes in China.

important bases for understanding the recent rupture field. Generally speaking, there is a good correlation between the directions of the long axis of isoseismal areas and of the earthquake fault. Obviously the direction and length of the source rupture controls the characteristics of isoseismal lines, and the geometric figure of the isoseismals is closely related to source dynamics. On the isoseismal map (Fig. 3), it could be clearly seen that there are two arcuate zones east of the Tibetan Plateau, one in the north, and the other in the south. The earthquake faults along these zones share a clockwise rotation and leftlateral shear. Strong earthquakes have often occurred along the southern zone (the Xianshihe fault). It is a conspicuously active seismic rupture zone in the innerland.

The data on source mechanisms throw light on the state or rupturing at depth of the source region. Based on seismic wave analysis, fault parameters of 106 strong and medium-sized earthquakes were derived. By comparison of these parameters with the regional tectonics, it is found (by the research group on source mechanism, SSB) that in the eastern part of China (such as North China), source mechanisms and regional tectonics are mostly consistent with each other. The strikes of faults are mainly NNE. In Middle China, the directions of fault planes of earthquakes are comparatively complicated; they are in directions of NE, NW, and NS, while in the west, most are not parallel with the regional main tectonic lines. For instance, in Tibet, earthquake ruptures run parallel to the developing NS-striking basins or to the NE- and NW-trending strike-slip active faults (YAN, 1981)

\section{Some' Characteristics of the Recent Crustal Rupture Field in China}

With analyses of data on the above mentioned respects, one may get an outline of the 


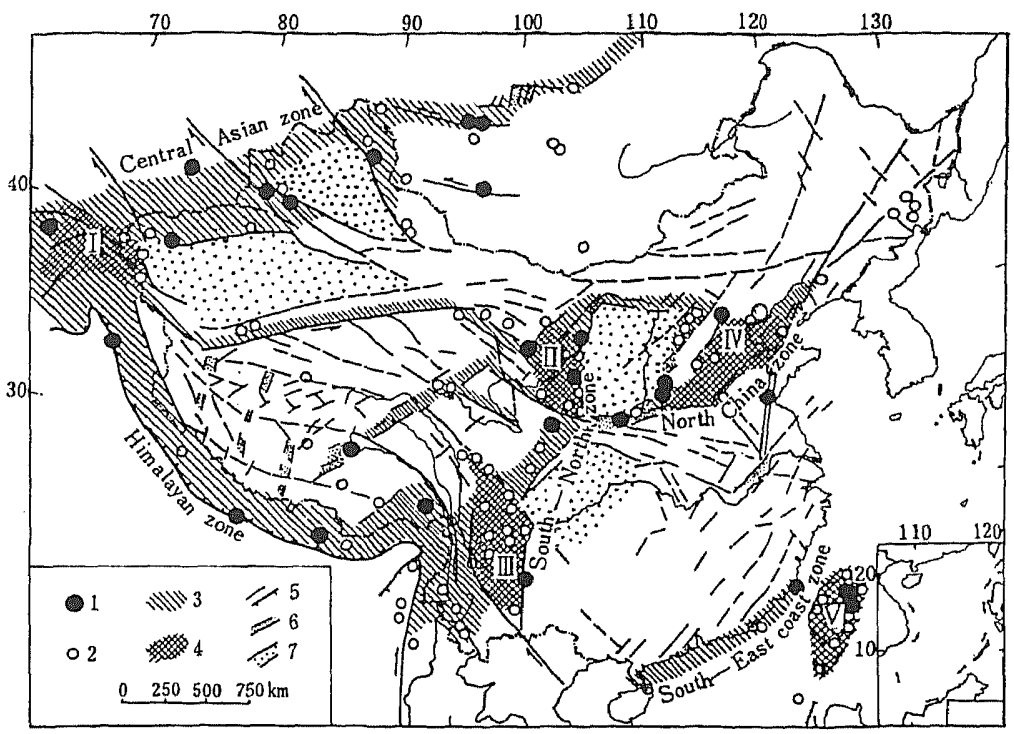

Fig. 4. Recent crustal rupturing zones with strong earthquakes in China and the adjacent areas. 1, Epicenter of a historical earthquake with $M=8 ; 2$, epicenter of a historical earthquake with $M=7-7.9 ; 3$, recent rupturing zone with strong earthquakes; 4 , recent rupturing area; 5 , active faults; 6 , rift; 7 , stable block.

recent crustal rupturing field in China and some knowledge about their relations to strong earthquake activities.

\section{I Distribution of recent crustal rupturing zones related to strong earthquakes}

On the continent of China, strong earthquakes of magnitude about 8 are distributed in definite areas and in obvious zones. There are mainly 4 such zones in China (Fig. 4). They are: the Pamir-Altai belt (or Central Asian zone), the North-South zone, the North China zone, and the Southeastern Coast zone. The large areas between these main zones, especially those within stable blocks, are places of small- and medium-sized earthquakes. Although active faults are distributed widely in these areas, they are not associated with strong earthquakes. The data of historical earthquakes during the last hundreds or even thousands of years, and of paleoearthquakes (or prehistorical earthquakes), indicate that the rupture zones which produce strong earthquakes are related only to some definite active faults in the continent.

Two enormous zones where crustal thickness abruptly changes, are the NE-striking Central Asian zone from Pamir to Altai extending further to Baikal (crustal thickness changes from 44 to $55 \mathrm{~km}$ ) and the North-South zone from Ningxia to Yunnan (from 44 to $52 \mathrm{~km}$ ) in the China continent (WANG et al., 1982). Data of geology, gravity, aeromagnetism, and remote sensing show that there are covered structures developed in prepaleozoic basement and in deeper tectonic layers along the two zones. The formation of these two seismic zones are directly related to the further convergence of the Indian plate on the Eurasian plate. Under the northward pressing of the Indian plate, a strong, 


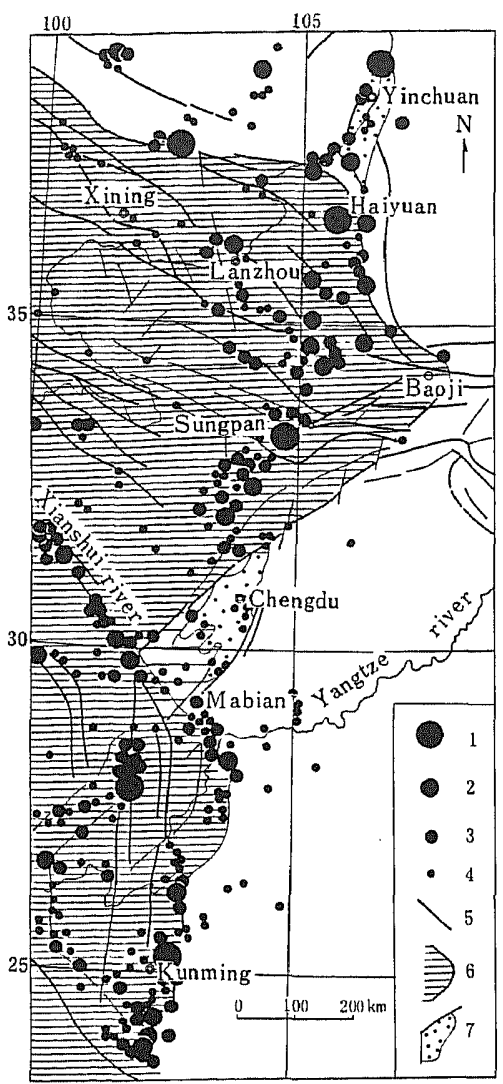

Fig. 5. The North-South strong earthquake zone. 1, Epicenter of a historical earthquake with $M=8 ; 2, M=7-7.9 ; 3, M=6-6.9 ; 4, M=5-5.9 ; 5$, active fault; 6 , compressional uplift regions of the Tibetan Plateau; 7, basin.

seismically active triangular area has been formed by the two zones with the Himalayan collision zone (WANG, 1983). To the north of the Himalayan zone, these two zones strike in the same directions of the maximum shearing strain of the regional stress field (TAPPONNIER and MOLNAR, 1976). They are the two huge new shear zones extending from the two ends of the Himalayan zone towards the innermost area of the continent along the pre-existing deep structures (Fig. 4). A series of strong earthquakes reflected that stress and strain rapidly accumulated and released along the two zones. The activities of many surface active faults and earthquakes in the western and central parts of China have also been controlled and affected by these large rupture zones. They are two important boundaries of recent intraplate movement in the eastern part of Asia.

The North-South zone actually consists of a series of discontinuous NS-trending structures lying within the range of $100-105^{\circ} \mathrm{E}$ (Fig. 5). Some segments are not cropped out, and the striking directions of buried fault may not always be in agreement with the surface structures. A linear NS-trending epicentral distribution from northern Sichuan to 
southern Gansu (roughly from Chengdu to Lanzhou in Fig. 4), intersects the surface EWstriking structures of Qinling (around $34 \mathrm{~N}$ ). This phenomenon illustrates that there exist approximately NS-striking structures and rupturing at depths.

From Pamir to Altai, and further to Baikal, is a huge NE-striking seismic belt within Central Asia (Fig. 4). Along this belt the surface structures strike mainly NW or nearly EW. They are interrupted by some NE-striking structures. On this belt the crustal thickness abruptly changes. On the neotectonic map, one may see the discontinuous ruptures and a series of rhombus-shaped sags between the ruptures. This reflects a left-lateral shear acting on NE-trending zone. Some NW-striking faults, however, show a right-lateral strike-slip. The focal depth of earthquakes in this area and the fact that there is no young magma activity in the deep crust suggest that the left-lateral shear largely occurs at the depth of 40 to $50 \mathrm{~km}$. In Central Asia, strong earthquakes of magnitudes about 8 generally concentrate in a belt striking NE. This indicates an existence of a new rupture belt along the NEstriking zone where crustal thickness abruptly changes.

\subsection{Recent rupture areas in the continent}

In the innerland of China, strong earthquakes occurring in definite areas are often concentrated in small regions. In such a region, earthquake fractures intersect each other forming a new rupturing area, where stress and strain is highly concentrated and released. These areas are tectonically complicated, taking a special position in the recent tectonic stress field. They are usually broken blocks in forms of rhombuses (see Fig. 4, II, III, and IV). For instance, at the northeastern margin of the Tibetan Plateau, rupturing and earthquake activity are quite active. There exists a clear recent crustal rupturing area.

The Pamir and the southern part of Sichuan and Yunnan Provinces are the two ends of the Himalayan collision zone. They are the two recent crustal rupture areas with intense seismicity. In North China, a crustal rupture area consists of many strong earthquake belts. The fracture patterns and the focal depth of earthquakes indicate that the ruptures are related with the fractured Precambrian basement having been pressed and pulled since the Mesozoic and Cenozoic times (see Fig. 4).

\subsection{Some characteristics of activity in recent crustal rupture zones}

In innerland areas, strong earthquakes and associated surface faults are usually distributed in belts and occur successively. Usually, rupture starts from one point at the edge of a block, and then a series of strong earthquakes occur successively within a certain period of time. A number of earthquake faults are produced during the process. The rupturing ends when the faults develop through the whole fault zone (DING, 1982 a). In such zones, the ruptures usually possess a similar mechanism, so they are products of the same stress field. In China, there are many such kinds of rupture zones (Fig. 6). One example is the rupture zone produced by a series of the strong earthquakes taking place from the 16th to 17 th century along the Fen River and Wei River (The fractures thus produced extended from the Xi'an to Pinggu, northeast of Beijing) (Fig. 7). The 1920-37 strong earthquake series at Hexi Corridor (Fig. 8), including the Haiyuan earthquake of $M=8$ and the Changma earthquake of $M=7.5$, produced a fault zone extending almost $1,000 \mathrm{~km}$. Also the 1966-76 strong earthquake series in the Hebei Plain and the series from 


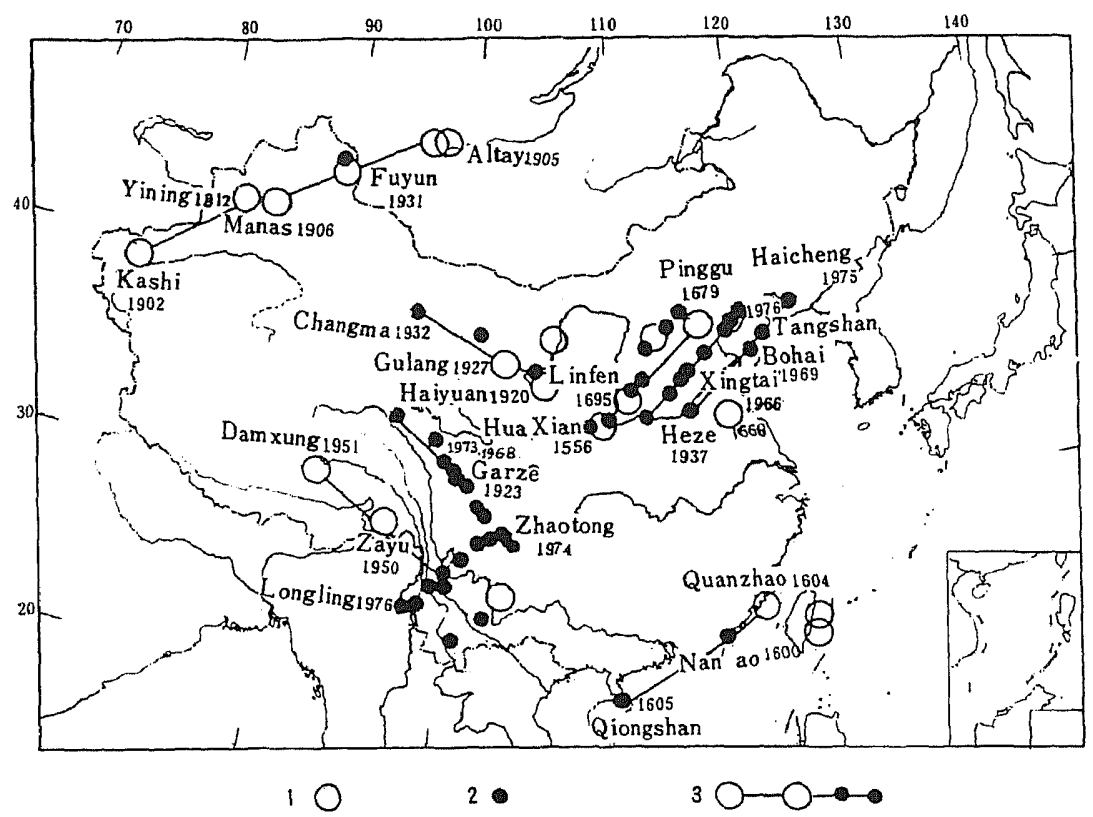

Fig. 6. Strong earthquake series in China. 1, Epicenter of a historical earthquake with $M=8 ; 2,6 \leq M \leq 7.9 ; 3$, series of strong earthquakes.

Ganze to Zhaotong are of this kind (Fig. 6). Within an interval of relatively short time, strong shocks occur successively along a rupture zone, where coseismic fractures appear in one segment after another until they extend to the whole belt, and then the period of seismicity quiescence follows (DING, 1982 a).

There is a phenomenon of migration of strong earthquake rupture zones. For instance, the seismicity record in the recent one hundred years shows that there were three large changes of regions of strong earthquake activities in the continent of China. From 1893-1917, strong earthquakes occurred mainly in the Pamir-Tianshan-Mongolia zone; from 1920-55, mainly in the North-South zone and around the eastern side of the Tibetan Plateau; and from 1965 to 1976 , strong earthquake activities took place in the North China region and in the southern part of the North-South zone. These three active areas are consistent with the three recent crustal rupture zones, the Central Asian zone, the NorthSouth zone and the North China zone. Moreover, the rupturing started from the west, migrating from one to another, eventually to the east.

Because of the limited data available, it is difficult to determine the migration laws of the seismic fracture zones in a larger time scale.

\subsection{Intrablock creeping and rupturing}

In the vast areas in-between the rupture zones associated with strong earthquakes, especially in the relatively stable blocks, only small- and medium-sized earthquakes occur. Strong earthquakes with magnitude about 8 have seldom (or never) happened. Active 


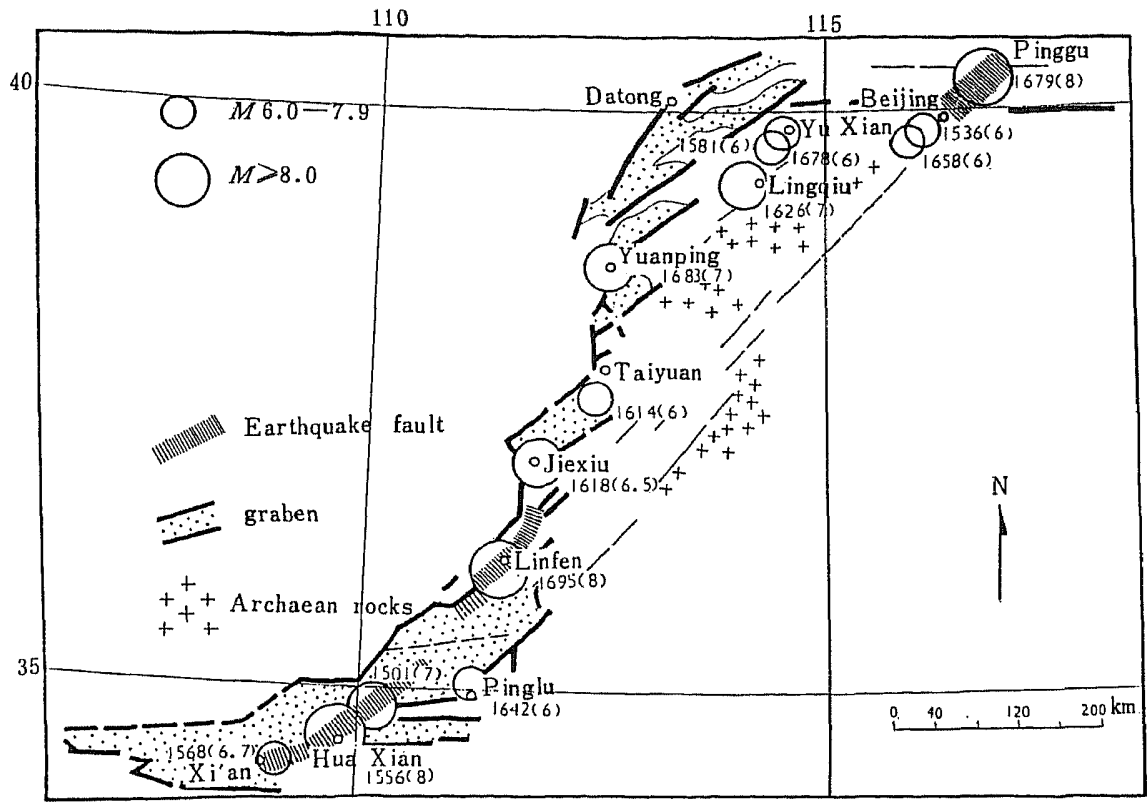

Fig. 7. The Fen-Wei Graben strong earthquake series (from the 16th to 17th century). The numbers in parentheses indicate earthquake magnitude. The attached numbers show the year of earthquake occurrence.

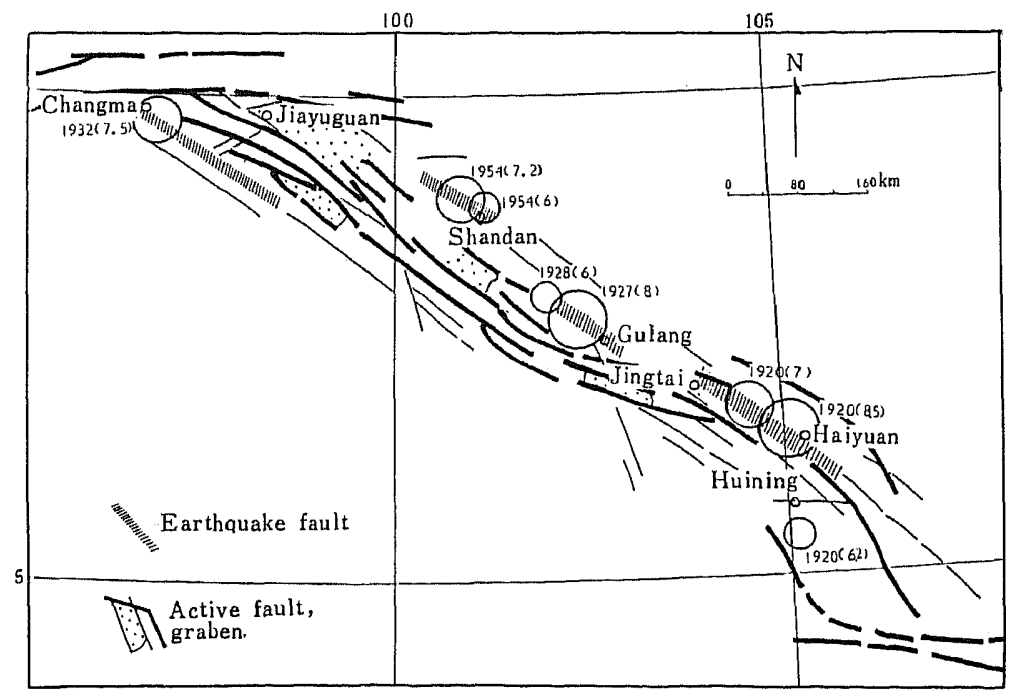

Fig. 8. The Hexi corridor strong earthquake series in 1920-1937. The numbers in parentheses indicate earthquake magnitude. The attached numbers show the year of earthquake occurrence. 


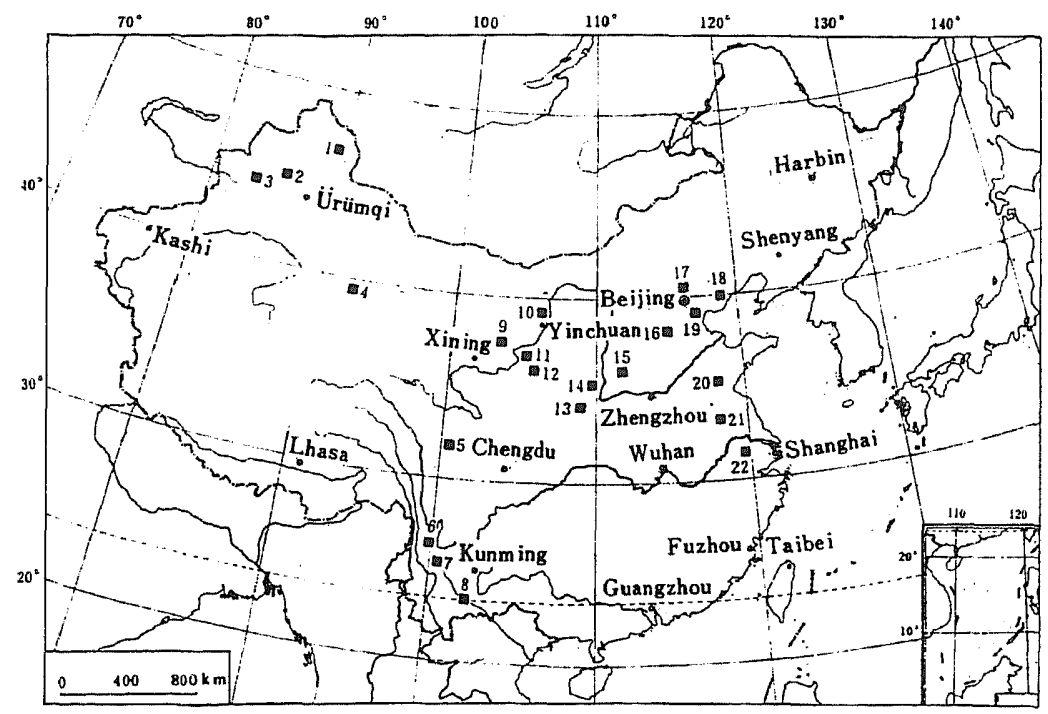

Fig. 9. Paleoearthquake sites recently discovered in China. 1, Fuyun; 2, Manas; 3, Nilka; 4, Altun; 5, Garzê; 6, Heqing; 7, Dali; 8, Red River; 9, Haiyuan; 10, Yinchuan Basin; 11, Zhongning; 12, Tianshui; 13, Weinan; 14, Hancheng; 15, Linfen; 16, Hebei Plain; 17, Near Beijing; 18, Tangshan; 19, Near Tianjin; 20, Tancheng; 21, Jiashan; 22, Liyang.

faults are also present in these areas, but they are not in such a mode as to cause strong earthquakes.

Having studied the San Andreas fault, the boundary of the plate, ALLEN (1979) made it clear that the fault consists of segments of various types of movement. Therefore, the fault can be divided into segments of stick-slip with strong earthquake activity and creeping segments without such activity. This division is obviously important in the assessment of strong earthquake hazard. Similar divisions could be applied to the continent of China. Instead of dividing a belt into two different kinds of segment, we divide a wide area into two different kinds of region. They are the rupture zones with active strong earthquakes which constitute the block boundaries, and intracontinental areas with few strong earthquakes (similar to creeping segments) lying between the former zones. It should be mentioned that fractures associated with small and medium earthquakes in the areas with few strong earthquakes are usually of conjugate form, crosscutting the regional structures. The ruptures are featured by regular networks. We may call this phenomenon intrablock creeping rupturing. In some relatively integrated blocks, e.g., the Tarim block, the creeping rupturing is more typical. In the eastern part of China, the phenomenon of cracking on the ground is very common. This is also a kind of small creeps and ruptures produced by tectonic activity in deep crust, which has been proven by the increased data (DrNG, $1982 \mathrm{~b}$ ).

\subsection{Recurrence interval of strong earthquakes in seismic rupture zones}

To assess the degrees of hazard of strong earthquakes on an active fault, it is necessary to solve the problem of recurrence interval of strong earthquakes (SIEH, 1981). All of the 16 
Table 1. Paleoearthquakes and their recurrent intervals on several active faults in China.

\begin{tabular}{|c|c|c|c|c|c|c|}
\hline \multirow{2}{*}{ Number } & \multirow{2}{*}{ Active faults } & \multirow{2}{*}{$\begin{array}{l}\text { Time and mag- } \\
\text { nitude of the } \\
\text { last strong } \\
\text { earthquake }\end{array}$} & \multirow{2}{*}{$\begin{array}{l}\text { Time and estimated } \\
\text { intensity of events }\end{array}$} & \multicolumn{2}{|c|}{$\begin{array}{l}\text { Recurrent intervals } \\
\qquad(\mathrm{yr})\end{array}$} & \multirow{2}{*}{ References } \\
\hline & & & & $\begin{array}{l}\text { The last } \\
\text { two events }\end{array}$ & $\begin{array}{l}\text { Average } \\
\text { value }\end{array}$ & \\
\hline 1 & $\begin{array}{l}\text { Fuyun fault, } \\
\text { Ertai, Xinjian }\end{array}$ & $\begin{array}{c}1930.8 .10 \\
M=8\end{array}$ & $\begin{array}{l}\text { A. in early Holocene } \\
\text { B. B.P. } 7,000-8,000 \mathrm{yr} \\
\text { C. B.P. } 2,500-3,500 \\
\text { D. B.P. } 685 \\
\text { E. B.P. } 230 \\
\text { F. B.P. } 150\end{array}$ & & $\begin{array}{c}\sim 2,000- \\
3,000\end{array}$ & $\begin{array}{l}\text { FENG and Song } \\
(1985)\end{array}$ \\
\hline 2 & $\begin{array}{l}\text { South-west } \\
\text { Huashan fault, } \\
\text { Haiyuan, Ningxia }\end{array}$ & $\begin{array}{c}1920.12 .16 \\
M=8.5\end{array}$ & $\begin{array}{l}\text { A. B.P. } 9,360 \pm 75 \mathrm{yr} \\
\text { B. No age data } M \sim 8.5 \\
\text { C. B.P. } 6,300 \pm 70 \\
\text { D. B.P. } 3,680 \pm 60\end{array}$ & $\sim 3,600$ & 2,325 & $\begin{array}{l}\text { LiU and ZHOU } \\
\text { (1985) }\end{array}$ \\
\hline 3 & $\begin{array}{l}\text { Zhongning- } \\
\text { Zhongwei fault, } \\
\text { Ningxia }\end{array}$ & $\begin{array}{c}1561.7 .25 \\
M=7.3\end{array}$ & $\begin{array}{l}\text { A. between } Q_{2}-Q_{3} \\
\text { B. in early Holocene } \\
M \text { unknown }\end{array}$ & & & $\begin{array}{l}\text { Haizhi Zhu et al. } \\
\text { (1980, personal } \\
\text { communication) }\end{array}$ \\
\hline 4 & $\begin{array}{l}\text { Helanshan front } \\
\text { F. Pingluo, } \\
\text { Ningxia }\end{array}$ & $\begin{array}{c}1739.1 .3 \\
M=8\end{array}$ & $\begin{array}{l}\text { A. in early Holocene } \\
\text { B. B.P. } 5,745 \pm 90 M \sim 8 \\
\text { C. No age data }\end{array}$ & $\sim 5,500$ & & $\begin{array}{l}\text { DENG and WANG } \\
(1984)\end{array}$ \\
\hline 5 & $\begin{array}{l}\text { Weihe fault, } \\
\text { Shanxi }\end{array}$ & $\begin{array}{c}1556.1 .23 \\
M=8\end{array}$ & B.P. $2,000 \mathrm{yr}$ & $\sim 1,570$ & & LI et al. (1982) \\
\hline 6 & $\begin{array}{l}\text { Tangshan- } \\
\text { Fengnan F., } \\
\text { Hebei }\end{array}$ & $\begin{array}{c}1976.7 .28 \\
M=7.8\end{array}$ & $\begin{array}{l}\text { A. B.P. } 14,865 \\
\text { B. B.P. } 7,665 \pm 105 \\
M=7.5-8\end{array}$ & $\sim 7,660$ & 7,400 & $\begin{array}{l}\text { WANG and Ll } \\
\text { (1984) }\end{array}$ \\
\hline 7 & $\begin{array}{l}\text { Tanlu fault, } \\
\text { Tanchen, } \\
\text { Shandong }\end{array}$ & $\begin{array}{c}1668.7 .25 \\
M=8.5\end{array}$ & $\begin{array}{l}\text { A. B.P. } 12,000 \\
\text { B. B.P. } 6,200 \\
\text { C. B.P. } 1,830 \\
\text { D. B.P. } 70\end{array}$ & $\sim 1,740$ & $\sim 3,000$ & $\begin{array}{l}\text { Weiming Gao ( } 1984 \text {, } \\
\text { personal communica- } \\
\text { tion) }\end{array}$ \\
\hline
\end{tabular}

\begin{tabular}{|c|c|c|c|c|c|c|}
\hline 8 & $\begin{array}{l}\text { Xianshuihe F. } \\
\text { Luhuo, Sichuan }\end{array}$ & $\begin{array}{r}1973.2 .6 \\
M=7.9\end{array}$ & $\begin{array}{l}\text { A. B.P. } 17,850 \pm 255 \\
\text { B. B.P. } 11,075 \pm 120 \\
\text { C. B.P. } 10,110 \pm 60 \\
\text { Strong earthquakes } \\
\text { occurred in } 1816 \text {, } \\
1923\left(I_{0}=X\right)\end{array}$ & $\sim 60$ & & $\begin{array}{l}\text { Rongchang Tang } \\
\text { et al. (1984, personal } \\
\text { communication) }\end{array}$ \\
\hline 9 & $\begin{array}{l}\text { Red River F. } \\
\text { Yunnan } \\
\text { (near Zhega) }\end{array}$ & & $\begin{array}{l}\text { At least } 4 \text { strong earth- } \\
\text { quakes in Holocene }\end{array}$ & & $\begin{array}{r}\text { about } \\
2,000\end{array}$ & $\begin{array}{l}\text { ALLEN et al. } \\
\text { (1984) }\end{array}$ \\
\hline
\end{tabular}


recorded strong earthquakes with magnitudes of 8 and above in the continent of China occurred in different places, except one. Therefore, one might believe that strong earthquakes do not recur in the same place in the continent. But this is not true. In recent years, studies on paleoearthquakes have been conducted by using geological and geophysical methods, especially trenching (Fig. 9). And as a result, in more than 10 places where earthquakes with magnitude of 8 and above occurred, e.g., Fuyun, Haiyuan, Yinchuan, and so on, the traces of paleoearthquakes were found. The information of paleoearthquakes tells us: earthquakes of magnitude about 8 do recur on some definite segments of faults in the continent. If one assumes that strong earthquakes do not recur in the same place, this is just because the time scale covered by the data is too short; the time period of historical earthquake records is shorter than the recurrence interval of large earthquakes.

The time span of strong earthquake recurrence depends evidently on the regions. On some active faults with larger slip rates in West China, such as the Central Asian zone and the North-South zone, the recurrence interval is usually within several hundred years to 2,000 or 3,000 years for earthquakes with magnitudes about 8 (DING, 1984). Whereas on the faults with lower slip rates in the east, such as the North China region, the recurrence interval is often as long as 2,000 or 3,000 years to 7,000 or 8,000 years. Of course, this only refers to one specific fault. As to a tectonic zone made up of many faults, the recurrence period of strong shocks may be much shorter. It may be only several hundred years for some seismic belts in the North China region (Table 1).

The discovery of paleoearthquake sites near the epicenters of strong earthquakes in several major recent crustal rupture zones indicates that the history of strong shocks on these rupture zones can be traced back in an even longer period (the whole Holocene). It seems, as mentioned above, that all these strong earthquake belts are determined by deep crustal structures and by the positions of these belts in the recent tectonic stress field. This situation will continue if there are no great changes in the regional tectonic stress field. And strong earthquakes will repeatedly occur along these rupture zones. Therefore, deeper and more detailed studies on the state of the recent crustal rupture field and on the laws of strong earthquake activities along each rupture zone will be of great significance for the realization of strong earthquake prediction.

\section{Conclusion}

(1) In general, the distribution of active faults reflects the basic recent rupturing frame of the crust. Therefore, study of active faults is of great importance to the realization of earthquake prediction. Since strong earthquakes do not occur on all active faults, the three following issues should be further studied: to find out segments and areas related to strong earthquakes from the complicated distribution of active faults; to study and determine the fault slip rates of these segments and the recurrence interval of strong earthquakes; and to study the regularity of migration of activities along these segments or in these areas.

(2) Active faults are widely distributed in the innerland of China. According to the data available, 4 major recent crustal rupture zones related to strong earthquake activity could be outlined. They are the Central Asian zone from Pamir to Altai, the North- 
South zone from Yunnan to Ningxia, the Southeastern Coastal zone, and the North China zone. The Himalayan zone is a collision zone of the Indian plate pushing in to the Eurasian plate. As to the Central Asian zone and the North-South zone, they are the two huge shear zones developed from the two syntaxis of the Himalayan collision zone along the preexisting deep structures into the inner part of the continent. And the formation of the Southeastern Coast zone is related to the influence from the West Pacific, whereas, there is much lower seismic activity in the vast creeping areas in-between the active zones with strong earthquakes.

(3) In the last 100 years, China has undergone three big changes in regions of strong earthquake activities. The migration of areas of strong earthquakes first started from the Central Asian zone, then to the North-South zone, and reached to the southern part of the North-South zone and North China zone. The three times of migration seem to relate to the ruptures occurring successively from west to east along the above-mentioned three huge rupture zones. Based on the data available, one may find that in different regions, the recurrence interval between strong earthquakes along active faults varies largely. To make clear the recurrence intervals of strong earthquakes on each recent crustal rupture zone and the migration law, the accumulation of a large amount of data on fault activity and paleoearthquakes is required.

\section{REFERENCES}

Allen, C. R., The modern San Andreas Fault, in Rubey, Vol. 1, The Geotectonic Development of California, ed. W. G. Ernst, pp. 511-534, Prentice-Hall, Englewood Cliffs, N.J., 1979.

Allen, C. R., Y. Han, K. E. Sieh, B. Zhang, A. R. Gillespie, and C. Zhu, Study of the Quaternary activity of the Red River fault, J. Seismol. Res., 7, 171-186, 1984 (in Chinese).

DENG, Q. and Y. WANG, The colluvium wedges, fault scarp and activity in Holocene at the Piedmont fault of Helanshan, Sci. Bull., 29, 557-560, 1984 (in Chinese).

DING, G., Strong earthquake series and Quaternary active fault zones in China, in Proceedings of the 3rd Symposium on Quaternary Research in China, pp. 184-194, 1982 a (in Chinese).

DiNG, G., Active tectonics and earthquakes, in Developments in Geology, Geological Society of China, pp. 145-154, Science Press, Beijing, 1982 b (in Chinese).

Ding, G., Active faults in China, in A Collection of Papers of International Symposium on Continental Seismicity and Earthquake Prediction, pp. 149-163, Seismological Press, Beijing, 1984 (in Chinese).

Feng, X. and H. Song, The paleoearthquakes on the Fuyun fault, in The Fuyun Earthquake Fault Zone. ed. G. Ding, pp. 120-141, Seismological Press, Beijing, 1985 (in Chinese).

$\mathrm{LI}, \mathrm{Y} ., \mathrm{H}$. HAN, and M. CHANG, Investigation of the Huaxian great earthquake damage and of the paleoearthquake traces, in Papers of Prehistoric Earthquakes and Quaternary Geology, Quaternary Research Association of China, pp. 42-49, Science Press of Shanxi, Shanxi Province, 1982 (in Chinese).

LiU, B. and J. ZHou, The prehistoric major earthquakes for Haiyuan active fault, Seismol. Geol., 7, No. 4, 11-22, 1985 (in Chinese).

MAtsuda, T., Estimation of future destructive earthquakes from active faults on land of Japan, $J$. Phys. Earth, 25, Suppl., S251-S260, 1977.

SIEH, K. E., A review of geological evidence for recurrence times of large earthquakes, in Earthquake Prediction-An International Review, Maurice Ewing Series 4, ed. D. W. Simpson and P. G. 
Richards, pp. 181-207, American Geophysical Union, Washington, D.C., 1981.

TAPPONNIER, P. and P. Molnar, Slip-line field theory and large-scale continental tectonics, Nature, 264, 319-324, 1976.

WANG, L., The source mechanisms of earthquake in Xinjiang and plate tectonics, Sci. Bull. Acad. Sin., 28, 810-813, 1983 (in Chinese).

WANG, Q., C. WU, H. LiU, and Y. Wor, Studies on the general distribution of crustal thickness and characteristics of crustal structure under the Asian Continent, Seismol. Geol., 4, No. 3, 1-10, 1982 (in Chinese).

WANG, T. and J. LI, The recurrence intervals of the strong earthquakes in Tangshan, Seismol. Geol., 6, No. 4, 77-83, 1984 (in Chinese).

YAN, J., Recent tectonics in the Qinghai-Xizang Plateau, Acta Geophys. Sin., 24, 385-393, 1981 (in Chinese). 